Quim. Nova, Vol. 35, No. 4, 738-742, 2012

\title{
EVALUATION OF PESTICIDE ADSORPTION IN GAS CHROMATOGRAPHIC INJECTOR AND COLUMN
}

\author{
Gevany Paulino de Pinho* e Flaviano Oliveira Silvério \\ Instituto de Ciências Agrárias, Universidade Federal de Minas Gerais, Av. Universitária, 1000, 39404-006 Montes Claros - MG, Brasil \\ Antônio Augusto Neves e Maria Eliana Lopes Ribeiro de Queiroz \\ Departamento de Química, Universidade Federal de Viçosa, Av. Peter Henry Rolfs, s/n, 36570-000 Viçosa - MG, Brasil
}

Recebido em 1/6/11; aceito em 12/10/11; publicado na web em 31/1/12

\begin{abstract}
Components in complex matrices can cause variations in chromatographic response during analysis of pesticides by gas chromatography. These variations are related to the competition between analytes and matrix components for adsorption sites in the chromatographic system. The capacity of the pesticides chlorpyrifos and deltamethrin to be adsorbed in the injector and chromatographic column was evaluated by constructing three isotherms and changing the column heating rate to 10 and $30{ }^{\circ} \mathrm{C} \mathrm{min}{ }^{-1}$. By using ANCOVA to compare the slope of calibration graphs, results showed that the higher the injector temperature $\left(310^{\circ} \mathrm{C}\right)$ the lower the pesticide adsorption. Also, deltamethrin influenced the adsorption of chlorpyrifos on the column chromatographic.
\end{abstract}

Keywords: matrix effects; pesticides; gas chromatography.

\section{INTRODUCTION}

The term "matrix-induced chromatographic response enhancement" or simply "matrix effect" is used to explain the differences in detector responses in pesticide analysis by gas chromatography (GC). This phenomenon is common when the recovery efficiency of pesticide is above $100 \%$ in the analysis of complex samples. ${ }^{1}$ This overestimated result primarily occurs when pesticide standard solutions prepared in pure solvent are used as reference in the quantification of the same pesticides in matrix extracts. ${ }^{2,3}$

These different chromatographic responses for pesticides in pure solvent and matrix extract have been attributed to analyte adsorption in the injector liner, chromatographic column and GC detector during analyses. ${ }^{4,5}$ Erney et al. ${ }^{2}$ discussed that part of a pesticide, when it is prepared in pure solvent, can be adsorbed onto the injector liner. However, when the pesticide is present in complex matrix extracts the adsorption in the liner is affected by competition with co-extractives. Greater quantities of pesticides are, therefore, eluted from the chromatographic column, enhancing the responses.

Currently, the matrix effect is only reduced in methods using procedures such as clean up ${ }^{2,5,6}$ and programmed temperature vaporizing (PTV) injection..$^{7-9}$ There are as well procedures that compensate the occurrence of the matrix effect, such as protective analytes, ${ }^{10-12}$ correction function ${ }^{13,14}$ and standard addition. ${ }^{15}$ Among the different methods to reduce the matrix effect, the use of standard solutions prepared in matrix extract produces better results. ${ }^{16,17}$ This method, nevertheless, has some limitations such as instability of some pesticides when stored in the presence of other matrix components, contamination of chromatographic system and consequently increase in maintenance and analysis costs.

Studies have shown that the intensity of the matrix effect is dependent on physicochemical properties of pesticides such as polarity, molecular weight, thermal stability, temperature of boiling analytes, etc. $^{4,18}$ In general, negative matrix effect is observed when there is degradation of the pesticide in injector, such as the analysis of captan and diclorfluanide. These pesticides are significantly less stable in pure solvent. On the other hand, stable compounds such as pyrethroids have presented positive matrix effect, and no decomposition was

\footnotetext{
*e-mail: gevanypp@ufmg.br
}

noticed for these pesticides in tested analysis in literature. ${ }^{19}$

Although matrix effects can be characterized by pesticide adsorption in the chromatographic system, up to now, no detailed studies have been reported in literature. The lack of information on this phenomenon's characteristics and the contribution of each part of the chromatographic system, particularly on injector and column, makes it difficult to draw up effective proposals for avoiding the matrix effect.

In a detailed study involving the matrix effect, the present work has investigated adsorption of two different pesticides (chlorpyrifos and deltamethrin) on a GC-Electron Capture Detector (ECD) system (injector and column). The results were compared statistically, and the contribution of each GC system component to the adsorption of chlorpyrifos and deltamethrin was also analyzed.

\section{EXPERIMENTAL}

\section{Reagents}

Stock standard solutions of chlorpyrifos $(99.0 \% \mathrm{~m} / \mathrm{m})$ and deltamethrin $(99.0 \% \mathrm{~m} / \mathrm{m})$ purchased from Chem Service (West Chester, PA, USA) were prepared in acetonitrile (Mallinckrodt/HPLC, Paris, France) to the concentration of $500 \mathrm{mg} \mathrm{L}^{-1}$ and stored at $4{ }^{\circ} \mathrm{C}$. From the dilution of stock solutions were prepared solutions of individual work to chlorpyrifos and deltamethrin at a concentration of $5.0 \mathrm{mg}$ $\mathrm{L}^{-1}$ in the same solvent.

\section{Chromatographic conditions}

For the pesticide determination, a gas chromatograph model GC-17-A from Shimadzu (Kyoto, Japan) equipped with an electron capture detector (ECD) was used.

Separations were carried out on a HP-5 capillary column (Agilent Technologies), stationary phase of 5\% phenyl - 95\% dimethylsiloxane ( $30 \mathrm{~m}$ x $0.25 \mathrm{~mm}$ i.d., $0.1 \mu \mathrm{m}$ film thickness) and nitrogen as carrier gas $\left(1.2 \mathrm{~mL} \mathrm{~min}^{-1}\right)$. The detector temperature was of $300{ }^{\circ} \mathrm{C}$ for all analyses, with an amount of $1 \mu \mathrm{L}$ of sample injected into the gas chromatograph with split ratio set at 1:5. To study the adsorption of pesticides in the injector and in the column the analytical conditions have been adjusted. 


\section{Chlorpyrifos and deltamethrin adsorption in the injector}

Pesticide adsorption in the injector was evaluated from analyses of chlorpyrifos and deltamethrin standard solutions, separately, at concentrations of 5, 20, 50, 100, 300 and $500 \mu \mathrm{g} \mathrm{L}{ }^{-1}$ (duplicate). The column temperature programming was adjusted initially at $200{ }^{\circ} \mathrm{C}$ and heated at a rate of $10{ }^{\circ} \mathrm{C} \mathrm{min}-1$ till $220^{\circ} \mathrm{C}$, and then it was heated at a rate of $50{ }^{\circ} \mathrm{C} \min ^{-1}$ up to $290{ }^{\circ} \mathrm{C}$ and held for $4 \mathrm{~min}$. After each analysis, the chromatographic system was thoroughly cleaned with acetonitrile injections in the same analytical conditions. The effect of injector temperature for chlorpyrifos was evaluated at 310, 280, $250,200,170$ and $150{ }^{\circ} \mathrm{C}$. However, the effect of injector temperature for deltamethrin was evaluated at 310,280 and $250{ }^{\circ} \mathrm{C}$ because of its characteristic high boiling temperature.

To evaluate the influence of deltamethrin during chlorpyrifos detection, adsorption isotherms were constructed with the injector at 310,280 and $250{ }^{\circ} \mathrm{C}$. Analyses were performed with standard solutions containing both chlorpyrifos and deltamethrin at concentrations ranging from 5 to $500 \mu \mathrm{g} \mathrm{L}^{-1}$.

\section{Chlorpyrifos and deltamethrin adsorption in the chromatographic column}

Adsorption of pesticides in the column was evaluated from the chromatographic responses obtained after injection of standard solutions containing individually chlorpyrifos and deltamethrin at the concentration range 5 to $500 \mu \mathrm{g} \mathrm{L}^{-1}$. Injections were carried out keeping the injector temperature fixed at $280{ }^{\circ} \mathrm{C}$ and using two oven temperature programming for column chromatography: a) initial temperature at $150{ }^{\circ} \mathrm{C}$ and heated with at a rate of $10^{\circ} \mathrm{C} \mathrm{min}^{-1}$ till 290 ${ }^{\circ} \mathrm{C}$, and held for $1 \mathrm{~min}$; b) initial temperature at $150{ }^{\circ} \mathrm{C}$ and heated at a rate of $30{ }^{\circ} \mathrm{C} \mathrm{min}-1$ till $290{ }^{\circ} \mathrm{C}$, and held for $4 \mathrm{~min}$. The same procedure was used for injections of standard solutions containing at the same time chlorpyrifos and deltamethrin, both in the concentration range of 5 to $500 \mu \mathrm{g} \mathrm{L}^{-1}$.

\section{RESULTS AND DISCUSSION}

\section{Chlorpyrifos and deltamethrin adsorption in the chromatographic system}

Chromatographic analysis involving pesticides chlorpyrifos, $l$-cyalothrin, cypermethrin and deltamethrin in extracts of various matrices have shown that the longer the retention time, the greater the matrix effect of each compound. ${ }^{20}$ These results correspond to with those reported by Menkissoglu-Spiroudi and Fotopoulou, ${ }^{16}$ who observed higher percentage of recovery for deltamethrin (higher retention time) in relation to chlorpyrifos (lower retention time), approximately 206 and $113 \%$ respectively. However, no study in the literature has investigated if during analysis of pesticide standard solutions in pure solvent, can occur competition between pesticides by active sites of GC, decreasing the adsorption of some analyte in the chromatographic system, similar to the effect of co-extractives in the analysis of pesticide in extracts.

So, the adsorption of analytes (chlorpyrifos and deltamethrin) in the injector and chromatographic column was studied separately. The physicochemical characteristics of the studied pesticides are shown in Table $1 .^{21}$

\section{Chlorpyrifos adsorption in the injector}

Adsorption of chlorpyrifos in the injector was evaluated by alterations in the chromatographic responses when analyzed standard
Table 1. Physicochemical characteristics of the pesticides studied ${ }^{21}$

\begin{tabular}{lcc}
\hline & Chlorpyrifos & Deltamethrin \\
\hline Structure & $350.59 \mathrm{~g} \mathrm{~mol}^{-1}$ & $505.21 \mathrm{~g} \mathrm{~mol}^{-1}$ \\
Molar mass & $42^{\circ} \mathrm{C}^{\circ}$ & $100{ }^{\circ} \mathrm{C}$ \\
Melting point & $0.94 \mathrm{mg} \mathrm{L}^{-1}$ & $0.0002 \mathrm{mg} \mathrm{L}^{-1}$ \\
w.s. & 4.70 & 4.60 \\
log $\mathrm{K}_{\text {ow }}$ & \begin{tabular}{c}
$\mathrm{S}$ \\
\hline
\end{tabular}
\end{tabular}

w.s. = water solubility $\left(20^{\circ} \mathrm{C}\right) ; \log \mathrm{K}=\log _{\mathrm{ow}}$ of octanol-water partition.

solutions in the range of 5 to $500 \mu \mathrm{g} \mathrm{L}^{-1}$ in acetonitrile. This concentration range was chosen on the basis of the maximum residue levels in vegetables allowed by the regulatory agencies for the pesticides under investigation..$^{22,23}$ The calibration curves were obtained with the injector at different temperatures $\left(310,280\right.$ and $\left.250{ }^{\circ} \mathrm{C}\right)$, as shown in Figure 1.

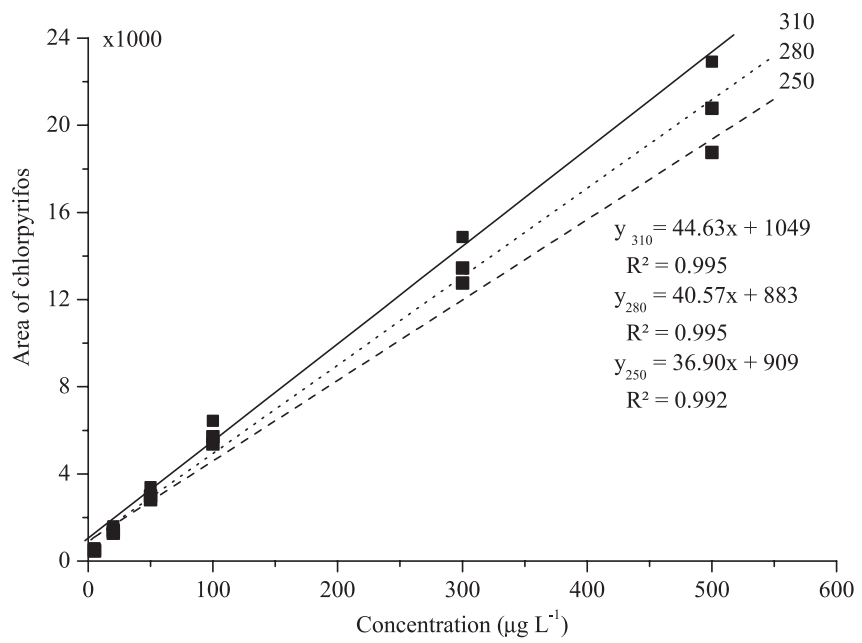

Figure 1. Analytical curves of chlorpyrifos standard solutions prepared in acetonitrile, in the concentration range from 5 to $500 \mu \mathrm{g} \mathrm{L} \mathrm{L}^{-1}$ and analyzed by $G C$-ECD with the injector at the following temperatures: (-) $310^{\circ} \mathrm{C}$; (----) $280^{\circ} \mathrm{C}$ and $(---) 250^{\circ} \mathrm{C}$

Analysis of covariance (ANCOVA) ${ }^{24,25}$ was applied in order to compare slopes and intercepts obtained with three temperatures. ANCOVA is a generic tool that can be used to compare regression curves. In the case of comparing only two curves, a conventional $F$-test can be applied. ${ }^{26}$ Data from each calibration set (two replicates) are fitted to straight lines using least-squares method. An $F$ statistic is calculated $\left(F_{\text {calc }}\right)$ for comparing the slopes and then the intercepts of the calibration curves: 310 with 280,280 with 250 and 310 with $250^{\circ} \mathrm{C}$. Such the $F$ calculated is defined as the quotient of $S^{2}{ }_{N}$ and $S_{D}^{2}\left(S^{2}\right.$ being the variance due to the difference between the reduced and full variability of residuals and $S^{2}$ the full variability of residuals): ${ }^{26}$

Comparison of slopes:

$$
\mathrm{F}=S_{N}^{2} / S_{D}^{2}=\left[\left(\mathrm{SS}_{\text {res }}^{\mathrm{R}}-\mathrm{SS}_{\text {res }}^{\mathrm{F}}\right) / m-1\right] / \mathrm{MS}_{\text {res }}^{\mathrm{F}}
$$

Comparison of intercepts:

$$
\mathrm{F}=S_{N}^{2} / S_{D}^{2}=\left[\left(\mathrm{SS}_{\text {res }}^{\mathrm{R}}-\mathrm{SS}_{\text {res }}^{\mathrm{F}}\right) /\left(v^{\mathrm{R}}-\mathrm{u}^{\mathrm{F}}\right)\right] / \mathrm{MS}_{\text {res }}^{\mathrm{F}}
$$


Table 2. Paired comparison of the slopes and intercepts estimated from calibrations obtained for the experiment of pesticides adsorption in the injector (250, 280 and $\left.310^{\circ} \mathrm{C}\right)$ and in the chromatographic column $\left(10\right.$ and $\left.30^{\circ} \mathrm{C} \mathrm{min}{ }^{-1}\right)$

\begin{tabular}{|c|c|c|c|c|c|c|c|c|}
\hline \multirow{3}{*}{ Calibration set } & \multicolumn{6}{|c|}{ Injector $\left({ }^{\circ} \mathrm{C}\right)$} & \multirow{2}{*}{\multicolumn{2}{|c|}{$\frac{\text { Column }\left({ }^{\circ} \mathrm{C} \mathrm{min}{ }^{-1}\right)}{10-30}$}} \\
\hline & \multicolumn{2}{|c|}{$250-280$} & \multicolumn{2}{|c|}{$280-310$} & \multicolumn{2}{|c|}{$250-310$} & & \\
\hline & $\mathrm{S}$ & I & $S$ & I & $S$ & I & $\mathrm{S}$ & I \\
\hline Chlorpyrifos & $2.48^{*}$ & 7.45 & $1.76^{*}$ & 5.27 & 5.91 & 17.72 & $0.73 *$ & $2.18^{*}$ \\
\hline Chlorpyrifos whit deltamethrin & $2.47 *$ & 7.42 & $0.14^{*}$ & $0.41^{*}$ & 4.98 & 14.93 & 29.34 & 88.02 \\
\hline Deltamethrin & $3.17 *$ & 9.51 & 59.46 & 178.4 & 46.97 & 140.9 & $0.01 *$ & $0.02 *$ \\
\hline
\end{tabular}

$\mathrm{S}=$ slopes; $\mathrm{I}=$ intercepts; $F_{\text {tab. }}=4.35$ for the slopes; $F_{\text {tab }}=4.32$ for the intercepts $(\mathrm{a}=0.05)$.

where $m$ is the number of slopes to be compared, $\mathrm{SS}_{\text {res }}^{\mathrm{F}}$ is calculated from the sums of squares of each individual regression and the mean square $\mathrm{MS}_{\text {res }}^{\mathrm{F}}$ is the quotient between the full residuals sum of squares and the full degrees of freedom (the sum of the degrees of freedom of each regression, $u^{\mathrm{F}}$ ), finally the reduced sum of squares $\mathrm{SS}_{\text {res }}^{\mathrm{R}}$ is given by the sums of squares of residuals resulting from a pooled regression performed with all regression lines. $F$-calculated $\left(F_{\text {calc }}\right)$ values were higher than the $F$-tabulated $\left(F_{\text {tab }}\right)$ values ones, considering a $95 \%$ confidence level for the intercepts. Slopes differ significantly only for temperatures 250 and $310{ }^{\circ} \mathrm{C}$ (Table 2).

It can be concluded that the higher the injector temperature the greater the slope, indicating an increased sensitivity of the analysis. This increase in response can be attributed to reduced pesticide adsorption in the injector at higher temperatures. On the basis of data from adjusted curves, the increase in chlorpyrifos response, with injector at $310{ }^{\circ} \mathrm{C}$ compared with $250{ }^{\circ} \mathrm{C}$ is approximately $21 \%$ $\left[\left(\mathrm{y}_{310}-\mathrm{y}_{250}\right) / \mathrm{y}_{250} \times 100\right]$.

After each analysis, pure acetonitrile was injected to clean the chromatographic system. Chlorpyrifos residues were detected after chromatographic analysis only for concentrations above $100 \mu \mathrm{g} \mathrm{L}^{-1}$, in the three temperatures of the injector. The area of the chlorpyrifos signal was less than $2 \%$ of the area obtained in the previous elution.

Injector temperatures lower than $250{ }^{\circ} \mathrm{C}$ produced anomalous behavior in chlorpyrifos chromatographic response. The equation obtained at $200{ }^{\circ} \mathrm{C}(\mathrm{y}=42.69 \mathrm{x}+353)$ shows a slope greater than the equation obtained at $250{ }^{\circ} \mathrm{C}(\mathrm{y}=36.90 \mathrm{x}+909)$, which means that more pesticide goes into the chromatographic column when the injector is at a low temperature. Besides, no pesticide residue was detected in the acetonitrile analysis performed after injections of chlorpyrifos standard solutions ranging from 5 to $500 \mu \mathrm{g} \mathrm{L}^{-1}$. It is important to emphasize that under these conditions the injector temperature is the same as the initial temperature of the column and therefore with no sample compound condensation at the entrance of the column.

However, during the analysis with the injector at $200{ }^{\circ} \mathrm{C}$, chlorpyrifos started to show two signals. Figure $1 \mathrm{~S}$ (supplementary material) shows the chromatograms of chlorpyrifos at $500 \mu \mathrm{g} \mathrm{L}^{-1}$ with the injector at $310,280,250,200,170$ and $150{ }^{\circ} \mathrm{C}$. Below $200^{\circ} \mathrm{C}$, the injector temperature is not enough for its vaporization.

\section{Deltamethrin adsorption in the injector}

In the study of deltamethrin adsorption in the injector, the analytical curves obtained at temperatures 250 and $280{ }^{\circ} \mathrm{C}$ were statistically similar, however there is a significant difference between the calibrations at 280 and $310^{\circ} \mathrm{C}$ with a level of confidence of $95 \%$ (Table 2). This means that with the injector at $310^{\circ} \mathrm{C}$, the slope was higher, indicating that the amount of deltamethrin which came in the chromatographic column was higher, as can be seen in Figure 2 .

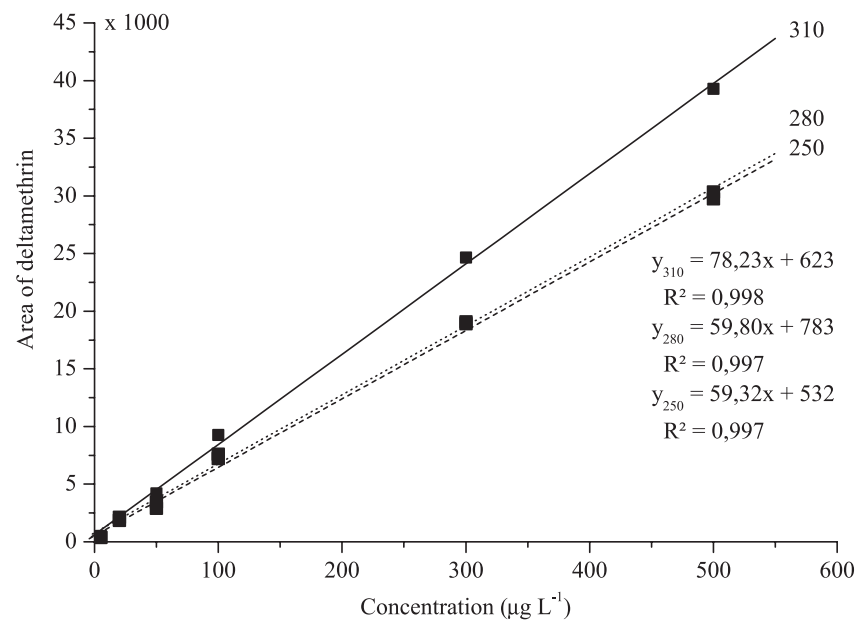

Figure 2. Analytical curves of deltamethrin standard solutions prepared in acetonitrile, in the concentration range from 5 to $500 \mu \mathrm{g} \mathrm{L} \mathrm{L}^{-1}$ and analyzed by $G C-E C D$ with the injector at the following temperatures: (-) $310{ }^{\circ} \mathrm{C}$; (---) $280^{\circ} \mathrm{C}$ and $(---) 250^{\circ} \mathrm{C}$

Considering the calibration for the injector at 250 and $310^{\circ} \mathrm{C}$, there is an increase of approximately $32 \%$ in the detector response $\left[\left(\mathrm{y}_{310}-\mathrm{y}_{250}\right) / \mathrm{y}_{250} \mathrm{x} 100\right]$. This quantity is greater than the result obtained for chlorpyrifos (21\%). These results suggest that the deltamethrin adsorption in the injector is greater than chlorpyrifos. For this reason, in the presence of co-extractives, the active sites are preferentially occupied by chemical constituents present in matrix extracts, and the matrix effect for deltamethrin is higher than for chlorpyrifos.

\section{Evaluation of influence of deltamethrin during chlorpyrifos detection}

Analytical curves were obtained from standard solutions containing the two pesticides at the same concentrations (5 to $\left.500 \mu \mathrm{g} \mathrm{L}^{-1}\right)$. When the solutions were analyzed with the injector at 250 and $310{ }^{\circ} \mathrm{C}$, both analytical curves showed coefficients statistically different with a level of confidence of $95 \%$ (Table 2). The percentage of variation in the area of chlorpyrifos $\left[\left(\mathrm{y}_{310}-\mathrm{y}_{250}\right) /\right.$ $\left.\mathrm{y}_{250} \mathrm{x} 100\right]$, obtained from analysis carried out with the injector at 250 and $310{ }^{\circ} \mathrm{C}$ was about $10 \%$ for all concentrations (Figure 3 ). This result is lower than the variation of the area of chlorpyrifos in the absence of deltamethrin (about 21\%).

Although deltamethrin is a less polar pesticide than chlorpyrifos, it has a high molecular weight, therefore a higher boiling temperature. Probably, when both pesticides are introduced into the injector (split), deltamethrin is more easily adsorbed on the liner surface, in the glass wool or in the column entrance, consequently reducing the chlorpyrifos interaction with surfaces in both temperatures. 


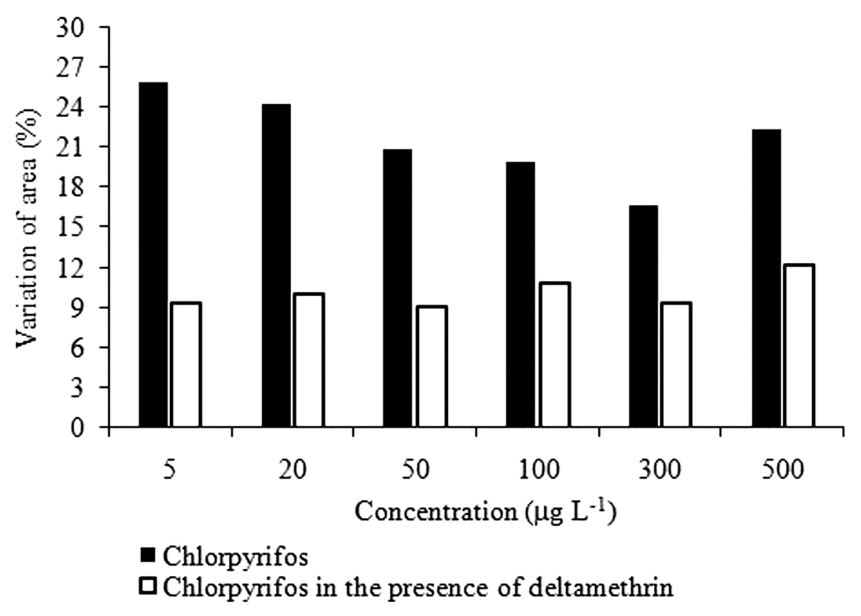

Figure 3. Percentage of variation in the area attributed to chlorpyrifos, and chlorpyrifos in the presence of deltamethrin at different concentrations, obtained from analysis carried out with the injector at $310^{\circ} \mathrm{C}$ and $250{ }^{\circ} \mathrm{C}$ $\left[\%=\left(\bar{A}_{310}-\bar{A}_{250}\right) / \bar{A}_{250} \times 100\right]$

\section{Chlorpyrifos and deltamethrin adsorption in the chromatographic column}

Few studies are found in literature describing matrix effect associated with chromatographic column. It is known, however, that the retention time of polar substances decreases with decreasing column polarity, indicating the effect of analyte adsorption. ${ }^{27}$ Evaluation of pesticide adsorption in the column can be carried out by keeping all chromatographic conditions (injector and detector temperature, flow, etc.) and varying the column temperature programming so that pesticides have different retention times. The study of chlorpyrifos and deltamethrin adsorption in the chromatographic column was performed as described in Table 3.

Table 3. Column temperature programming used to study chlorpyrifos and deltamethrin adsorption in the chromatographic column

\begin{tabular}{cccc}
\hline \multirow{2}{*}{ Programming } & \multirow{2}{*}{$\begin{array}{c}\text { Analysis time } \\
(\text { min })\end{array}$} & \multicolumn{2}{c}{ Retention time (min) } \\
\cline { 3 - 4 } & 15 & Chlorpyrifos & Deltamethrin \\
\hline A & 8.7 & 3.5 & 14.1 \\
B & 8.5 & 7.3 \\
\hline
\end{tabular}

Using different column heating rates, calibration curves were prepared from injections of chlorpyrifos standard solutions in acetonitrile (duplicate). Equations of calibration curves obtained for the heating rates at 10 and $30{ }^{\circ} \mathrm{C} \mathrm{min}-1$ were $y=50.69 x+1542\left(\mathrm{R}^{2}=\right.$ $0.993)$ and $y=45.74 x+1256\left(R^{2}=0.992\right)$, respectively. No significant difference were found between both types of analytical curves (slope and intercept), with a level of confidence of 95\% (Table 2). Likewise, deltamethrin adsorption in the chromatographic column was also evaluated by varying the pesticide retention time. $F$-test values showed that in the case of $10{ }^{\circ} \mathrm{C} \mathrm{min}-1$ and $30{ }^{\circ} \mathrm{C} \mathrm{min}-1$ series, there is no significant difference between calibrations (Table 2).

However, when standard solutions containing chlorpyrifos in the presence of deltamethrin $\left(5\right.$ to $\left.500 \mu \mathrm{g} \mathrm{L}^{-1}\right)$ were analyzed with heating rate of 10 and $30{ }^{\circ} \mathrm{C} \mathrm{min}-1$, there is significant difference between calibrations (Table 2). When comparing the results, one can suggest a competition between deltamethrin and chlorpyrifos for active sites of the chromatographic column. This result can best be seen in Figure 4 which compares the area of chlorpyrifos in the presence and absence of deltamethrin.

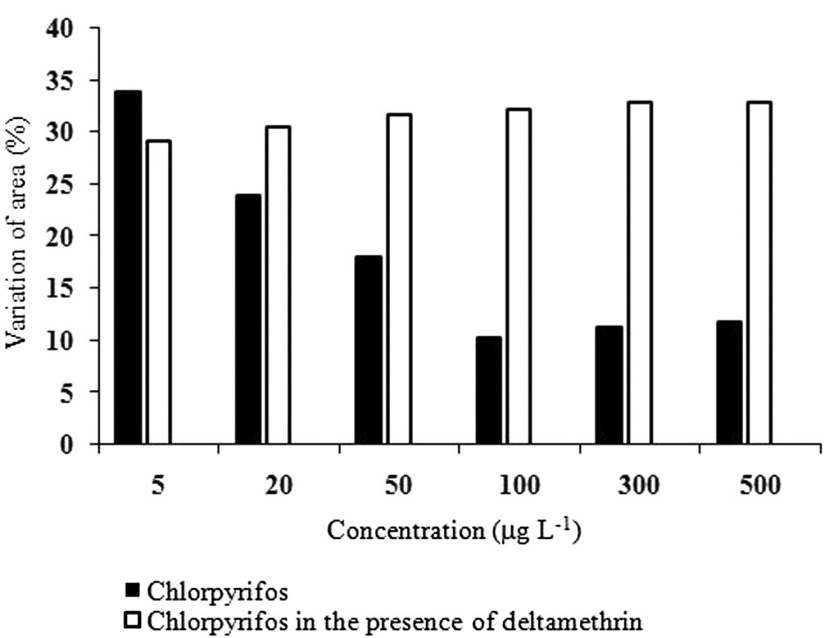

Figure 4. Percentage of variation in the area attributed to chlorpyrifos, and chlorpyrifos in the presence of deltamethrin at different concentrations, obtained from analysis carried out applying a column heating rate at 10 and $30{ }^{\circ} \mathrm{Cmin}^{-1}\left[\%=\left(\bar{A}_{10}-\bar{A}_{30}\right) / \bar{A}_{30} \times 100\right]$

\section{CONCLUSION}

A method to characterize the adsorption of two pesticides using GC-ECD has been proposed. Statistical tools were used to show that the chlorpyrifos and deltamethrin adsorption in the chromatographic system was affected by variations in injector temperature and heating rate of chromatographic column. For this reason, to reduce possible adsorptions of pesticides and thus minimize problems with matrix effect, the chromatographic analysis should be carried out at higher injector temperatures $\left(310^{\circ} \mathrm{C}\right)$.

Also, the proposed strategy provides a very simple way to verify that chlorpyrifos adsorption in the injector was influenced by deltamethrin. The protective effect of deltamethrin (pesticide of higher retention time) was confirmed in the chlorpyrifos analysis at different injector temperatures.

Deltamethrin presence also influenced chlorpyrifos adsorption in the chromatographic column. Therefore, we believe that additional studies should be necessary to investigate the adsorption of other pesticides in the chromatographic system to explain the competition between the pesticides, which may be of great interest for residue laboratories.

\section{SUPPLEMENTARY MATERIAL}

Available at http://quimicanova.sbq.org.br, in PDF file, with free access.

\section{ACKNOWLEDGEMENTS}

We thank the Brazilian Agencies: Conselho Nacional de Desenvolvimento Científico e Tecnológico (CNPq) and Fundação de Amparo à Pesquisa do Estado de Minas Gerais (FAPEMIG) for financial support.

\section{REFERENCES}

1. Hajslová, J.; Holdova, K.; Kocourek, V.; Poustka, J.; Godula, M.; Cuhra, P.; Kempny, M.; J. Chromatogr., A 1998, 800, 283.

2. Erney, D. R.; Gillespie, A. M.; Gilvydis, D. M.; J. Chromatogr., A 1993, 638, 57.

3. Pinho, G. P.; Neves, A. A.; Queiroz, M. E. L. R.; Silvério, F. O.; Quim. Nova 2009, 32, 987. 
4. Poole, C. F.; J. Chromatogr., A 2007, 1158, 241.

5. Schenck, F. J.; Lehotay, S. J.; J. Chromatogr., A 2000, 868, 51.

6. Zrostikova, J.; Hajslova, J.; Godula, M.; Mastovska, E.; J. Chromatogr., A 2001, 937, 73.

7. Pereira, A. S.; Aquino Neto, F. R.; Quim. Nova 2000, 23, 370.

8. Godula, M.; Hajslová, J.; Mastouska, K.; Krivanková, J.; J. Sep. Sci. 2001, 24, 355.

9. Rantakokko, P.; Yritys, M.; Vartiainen, T.; J. Chromatogr., A 2004, 1028, 179 .

10. Anastassiades, M.; Mastovská, K.; Lehotay, S. J.; J. Chromatogr., A 2003, 1015, 163.

11. Erney, D. R.; Poole, C. F.; J. High Resol. Chromatogr. 1993, 16, 501.

12. Kirchner, M.; Huskova, R.; Matisova, E.; Mocak, J.; J. Chromatogr., A 2008, 1186, 271.

13. Hernandez, T. M. E.; Egea, G. F. J.; Cuadros-Rodrlguez, L.; Lopez, E. A.; Martinez, V. J. L.; Chromatographia 2003, 57, 657.

14. Cuadros-Rodriguez, L.; García-Campana, A. M.; Almansa-López, E.; Egea-Gonzáles, F. J.; Cano, M. L. C.; Frenich, A. G.; Vidal, J. L. M.; Anal. Chim. Acta 2003, 478, 281.

15. Frenich, A. G.; Vidal, J. L. M.; Moreno, J. L. F.; Romero-González, R.; J. Chromatogr., A 2009, 1216, 4798.

16. Menkissoglu-Spiroudi, U.; Fotopoulou, A.; Int. J. Environ. Anal. Chem. 2004, 84, 15.
17. Vidal, J. L. M.; Arrebola, F. J.; Frenich, A. G.; Fernandez, J. M.; Mateu-Sanchez, M.; Chromatographia 2004, 59, 321.

18. Sanchez-Brunete, C.; Albero, B.; Martín, G.; Tadeo, J. L.; Anal. Sci. 2005, 21, 1291.

19. Kocourek, V.; Hajslova, J.; Holadová, K.; Poustka, J.; J. Chromatogr., A 1998, 800, 297.

20. Pinho, G. P.; Neves, A. A.; Queiroz, M. E. L. R.; Silvério, F. O.; Starling, M. A. V. M.; Quim. Nova 2010, 33, 909.

21. Specifications and Evaluations for Agricultural Pesticides, http://www. fao.org/, accessed in September 2011.

22. http://www.anvisa.gov.br/toxicologia/monografias, accessed in May 2011.

23. http://www.codexalimentarius.net/mrls, accessed in May 2011.

24. Campanã, A. M. G.; Rodríguez, L. C.; Munõz, J. A.; Barrero, F. A.; J. AOAC Int. 1997, 80, 657.

25. Sendra, J. B.; Rodríguez, L. C.; Campanã, A. M. G.; Pure Appl. Anal. Chem. 1998, 1, 115.

26. Rodríguez, L. C.; Campanã, A. M. G.; Almansa-López, E.; Egea-Gonzáles, F. J.; Cano, M. L. C.; Frenich, A. G.; Marínez-Vidal, J. L.; Anal. Chim. Acta 2003, 478, 281.

27. Grob, K.; Grob, G.; J. Chromatogr., A 1981, 219, 13. 